\title{
Age, growth, mortality and reproductive seasonality of jolthead porgy, Calamus bajonado, from Florida waters
}

\author{
Michael L Burton ${ }^{\text {Corresp., }}{ }^{1}$, Jennifer C Potts ${ }^{1}$, Jordan Page ${ }^{1}$ ， Ariel Poholek ${ }^{1}$ \\ ${ }^{1}$ National Marine Fisheries Service, Beaufort Laboratory, Beaufort, North Carolina, USA \\ Corresponding Author: Michael L Burton \\ Email address: michael.burton@noaa.gov
}

Ages of jolthead porgy (Calamus bajonado Schneider 1801) $(n=635)$ from Florida commercial and recreational fisheries from 2008 - 2016 were determined using sectioned sagittal otoliths. We determined, using edge-type analysis, that opaque zones were annular, forming March - June (peaking in April). Jolthead porgy ranged from 1 - 13 years, and the largest fish measured $680 \mathrm{~mm}$ TL (total length, $\mathrm{mm}$ ). Body size relationships for jolthead porgy were $\mathrm{TL}=1.09 \mathrm{FL}+20.44\left(n=622, r^{2}=0.99\right), \mathrm{FL}=0.90 \mathrm{TL}-14.26(n=$ $\left.622, r^{2}=0.99\right)$, and $\mathrm{W}=1.1 \times 10^{-5} \mathrm{TL}^{3.06}(n=577)$, where $\mathrm{W}$ is total weight (grams, $g$ ) and $\mathrm{FL}$ is fork length $(\mathrm{mm})$. The von Bertalanffy growth equation for jolthead porgy was $L_{t}=$ 737 ( $1-^{e-0.14(t+2.02))}(n=635)$. Point estimate of natural mortality was $M=0.32$, while agespecific estimates of $M$ ranged from $0.58-0.17 y^{-1}$ for ages $1-13$. Catch curve analysis estimated the instantaneous rate of total mortality $Z=0.70$, while instantaneous rate of fishing mortality $F$ was 0.38 . Macroscopic staging of female gonads indicated the presence of hydrated oocytes from December - March, and GSI data indicates that peak spawning in females occurs during March. This study presents the first published findings of life history parameters for jolthead porgy from the Atlantic waters off the southeastern United States. 
1 Age, growth, mortality and reproductive seasonality of jolthead porgy, Calamus bajonado, from 2 Florida waters.

3

4

5

6

7

8

9

10

11

12

13

14

15

16

17

18

19

20

21

22

23

24

25

26

27

28

29

30

31

32

33

34

35

36

37

38

39

40

41

42

Michael L. Burton, Jennifer C. Potts, Jordan Page and Ariel Poholek. National Marine Fisheries

Service, Southeast Fisheries Science Center, Beaufort Laboratory, Beaufort NC 28516.

Corresponding Author: Michael L. Burton. National Marine Fisheries Service, Southeast

Fisheries Science Center, Beaufort Laboratory, Beaufort NC 28516

$\mathrm{Ph}:$ 252-728-8756. < Michael.burton@noaa.gov>

(1)


43 ABSTRACT. Ages of jolthead porgy (Calamus bajonado Schneider 1801) $(n=635)$ from

44 Florida commercial and recreational fisheries from 2008 - 2016 were determined using sectioned

45 sagittal otoliths. We determined, using edge-type analysis, that opaque zones were annular,

46 forming March - June (peaking in April). Jolthead porgy ranged from 1 - 13 years, and the

47 largest fish measured $680 \mathrm{~mm}$ TL (total length, $\mathrm{mm}$ ). Body size relationships for jolthead porgy

48 were $\mathrm{TL}=1.09 \mathrm{FL}+20.44\left(n=622, r^{2}=0.99\right), \mathrm{FL}=0.90 \mathrm{TL}-14.26\left(n=622, r^{2}=0.99\right)$, and

$49 \mathrm{~W}=1.1 \times 10^{-5} \mathrm{TL}^{3.06}(n=577)$, where $\mathrm{W}$ is total weight (grams, $\left.\mathrm{g}\right)$ and FL is fork length $(\mathrm{mm})$.

50 The von Bertalanffy growth equation for jolthead porgy was $L_{t}=737\left(1-\mathrm{e}^{-0.14(\mathrm{t}+2.02)}\right)(\mathrm{n}=635)$.

51 Point estimate of natural mortality was $M=0.32$, while age-specific estimates of $M$ ranged from

$520.58-0.17 \mathrm{y}^{-1}$ for ages $1-13$. Catch curve analysis estimated the instantaneous rate of total

53 mortality $Z=0.70$, while instantaneous rate of fishing mortality $F$ was 0.38 . Macroscopic staging

54 of female gonads indicated the presence of hydrated oocytes from December - March, and GSI

55 data indicates that peak spawning in females occurs during March. This study presents the first

56 published findings of life history parameters for jolthead porgy from the Atlantic waters off the

57 southeastern United States.

INTRODUCTION

Jolthead porgy (Calamus bajonado Schneider 1801) is one of the largest porgies (Family Sparidae) in the western Atlantic, capable of attaining lengths of almost $800 \mathrm{~mm}$ total length (TL). The species is distributed widely in the western Atlantic Ocean, from Rhode Island southward to Brazil, including Bermuda and throughout the Caribbean and into the Gulf of Mexico to northwest Florida (Randall \& Caldwell, 1966), although it typically is not found in 65 fishery catches north of Cape Canaveral, Florida (Dixon \& Huntsman, 2004). Adults normally 
66 inhabit subtropical to tropical waters of the coastal and insular shelfs at depths from $0-200 \mathrm{~m}$

67 (Smith, 1997). Juveniles or sub-adults have been collected from seagrass beds in the U. S. Virgin

68 Islands (Randall \& Caldwell 1966). Like many members of the family Sparidae, the species

69 exhibits protogynous hermaphrodism (Dubovitskij, 1974, in Claro, Lindeman \& Parenti, 2001).

70 Jolthead porgy is not a target species of reef fisheries in the southeastern United States

71 (SEUS, North Carolina to Florida Keys, including the Dry Tortugas) but is an important

72 secondary species in the snapper-grouper fishery. The following raw landings data may be found

73 in the supplemental data file, in the Landings tab. Estimated annual landings from headboats

74 (vessels carrying at least seven anglers engaged in recreational fishing) sampled by the Southeast

75 Region Headboat Survey (SRHS) averaged 1,886 fish annually from 1981 - 2015, with an

76 average of $62 \%$ of those coming from Florida waters. Estimated annual numbers of fish landed

77 in the SEUS by anglers fishing from private recreational boats and charter boats averaged 73,381

78 fish from 1981 - 2015, with 98\% of those landed in Florida waters. Commercial fisheries

79 landings from the SEUS are exclusively from Florida, averaging $435 \mathrm{~kg}$ annually from 1996 -

80 2014. We posit that the lack of commercial landings from outside Florida may be due to non-

81 retention of this less important species by commercial fishermen, while lack of private

82 recreationally caught jolthead porgy might be attributable to a species identification issue

83 (lumping of jolthead porgy with other porgy species). However, we queried the Southeast Reef

84 Fish Survey (SERFS) database, a long-term chevron trap fishery-independent survey that

85 samples the SEUS, for occurrences of jolthead porgy being captured in traps deployed off North

86 Carolina or South Carolina, and found no instances of capture in the traps back to 1990. Fisheries

87 landings are temporally variable with no apparent increasing or decreasing trends. 
88

89

90

91

92

93

94

95

96

97

Jolthead porgy is currently included in the South Atlantic Fishery Management Council's Snapper-Grouper Fishery Management Plan (SAFMC, 2017). Jolthead porgy is managed by inclusion in the 20-fish aggregate bag limit for recreational fisheries. Recreational catches are further regulated by a porgy complex (jolthead porgy; knobbed porgy Calamus nodosus Randall \& Caldwell, 1966; Whitebone porgy Calamus leucosteus Jordan and Gilbert 1885; saucereye porgy Calamus calamus Valenciennes 1830; and scup Stenotomus chrysops Linnaeus 1766) aggregate annual catch limit (ACL), or quota, of 48,495 kg (SAFMC, 2017). The commercial fishery is managed with an ACL of $16,487 \mathrm{~kg}$ for the porgy complex.

The recreational quota for the porgy complex was reached on September 17, 2014, triggering the first closure of the recreational fishery for those five species. While there was limited life history information on some of these species in SEUS waters (knobbed porgy - Borden, 2001, Horvath, Grimes \& Huntsman, 1990; whitebone porgy - Waltz, Roumillat \& Wenner, 1982, Sedberry 1989) there were no published studies on jolthead porgy to assist fishery managers in determining appropriate ACLs. This lack of basic biological information on an important species was a prime motivator behind this study. Knowledge about growth characteristics and natural mortality are important inputs into stock assessments that lead to the development of annual quotas, or overfishing limits (Carruthers et al., 2017). We used sagittal otoliths and gonad samples collected through dockside sampling programs to provide the first published information on age-growth parameters, natural mortality rates and reproductive seasonality for jolthead porgy in the SEUS, filling in an important gap for this data-poor species.

\section{MATERIALS AND METHODS}

\section{Sampling}



collected by the SRHS in 2008 and 2011. Sampling occurred year round, All samples came from Florida, with southeast Florida (Ft. Pierce through Miami) accounting for $30 \%(n=190)$ and the Florida Keys accounting for $70 \%(n=448)$. The majority of samples were collected from fish

117 caught by headboat anglers $(n=546)$, with private recreational anglers/charterboat anglers $(n=$

118 7) and the commercial fisheries sector $(n=85)$ accounting for the rest. All specimens were captured by either conventional vertical hook and line gear or divers with spears. Total lengths (TL) and/or fork lengths (FL) of specimens were recorded in millimeters (mm). Whole weight (W) in grams was recorded for fish landed in the recreational headboat fishery. Fish landed by commercial fisheries were eviscerated at sea and were excluded from the $\mathrm{W}$ - TL regression analysis. Sagittal otoliths were removed during dockside sampling and stored dry in coin envelopes.

\section{Reproductive seasonality}

Gonads were collected during 2015-2016 from fish sampled from headboats, as commercially caught fish were eviscerated at sea prior to sampling. Sex was assigned using macroscopic examination of the gonads (rounded cross section, females; triangular cross section, males) and recorded. Whole gonads were weighed to the nearest 0.01 grams, macroscopically staged using the general terminology of Brown-Peterson et al. (2011) and preserved in 10\% buffered formalin for future histological processing and determination of timing of transition from female to male, which cannot be done reliably macroscopically. Reproductive seasonality was assessed for this

133 study using a gonadosomatic index (GSI) for females, calculated as 


$$
\text { GSI }=(\operatorname{gonad} w e i g h t / \text { whole weight }) * 100 .
$$

135

\section{Age determination and timing of opaque zone formation}

Otoliths were sectioned on a low-speed saw, following the methods of Potts \& Manooch (1995). Three serial $0.5 \mathrm{~mm}$ sections were taken from the transverse plane near the otolith core. The sections were mounted on microscope slides with thermal cement and covered with mounting medium before analysis. The sections were viewed under a dissecting microscope at 12.5X using transmitted light.

Age determination was based on recording an opaque zone count and edge type code by an experienced reader (MLB) with extensive experience interpreting otolith sections (Burton, 2001; Potts, Burton \& Myers, 2016) with no knowledge of date of capture or fish size for each sample. The edge codes refer to the type of zone, opaque or translucent, and in the case of translucent zones the amount of that zone between the last opaque zone formed and the otolith section edge. The codes used are outlined below:

$1=$ opaque zone forming on the edge of the otolith section; $2=$ narrow translucent zone on the edge, generally $<30 \%$ of the width of the previous translucent zone;

$3=$ moderate translucent zone on the edge, generally $30 \%-60 \%$ of the width of the previous translucent zone;

$4=$ wide translucent zone on the edge, generally $>60 \%$ of the width of the previous translucent zone (Harris et al., 2007).

To ensure consistency in interpretation of the growth zones on the otolith, a subset of the otolith sections ( $\mathrm{n}=520 ; 82 \%)$ were then read by a second reader (JP), and an index of betweenreader average percent error (APE) was calculated, following the methodology of Beamish \& 
157 Fournier (1981). Where readings for a specimen disagreed, the sections were viewed again

158 together. If consensus was reached the sample was retained; otherwise, it was excluded from

159 further analysis.

160 Timing of opaque zone formation was assessed using edge analysis. The edge types were

161 plotted by month of capture to determine if the opaque zones were deposited primarily in one

162 season or month. Based upon edge frequency analysis, all samples were assigned a calendar age,

163 obtained by increasing the opaque zone count by one if the fish was caught before that year's

164 opaque zone was formed and had an edge which was a moderate to wide translucent zone (type 3

165 or 4). Fish caught during the time of year of opaque zone formation with an edge type of 1 or 2 ,

166 as well as fish caught after the time of opaque zone formation, were assigned a calendar age

167 equivalent to the opaque zone count.

168 Growth

169 Growth of jolthead porgy was estimated using the Von Bertalanffy (1938) growth model:

$170 \quad L_{t}=L_{i n f}\left(1-e^{\left(-K\left(\mathrm{t}-t_{0}\right)\right)}\right)$ where $L_{\text {inf }}=$ theoretical maximum length, $K=$ Brody growth

171 coefficient (rate at which maximum size is attained), and $t_{0}=$ theoretical age at size 0 .

172 Parameters were estimated from observed length at age using AD Model Builder estimation

173 software (Otter Research Ltd., Sidney, B.C., Canada) [Mention of trade names or commercial

174 companies is for identification purposes only and does not imply endorsement by the National

175 Marine Fisheries Service, NOAA]. To account for growth of the fish throughout the year before

176 or after its "birthday", the calendar age of the fish $\left(\mathrm{Age}_{\mathrm{c}}\right)$ was adjusted for the time of year

177 caught $\left(\mathrm{Mo}_{\mathrm{c}}\right)$ compared to month of peak spawning, or "birthdate", $\left(\mathrm{Mo}_{\mathrm{b}}\right)$, determined from the

178 reproductive component of this study, thus creating a fractional, or monthly biological age,

$179\left(\right.$ Age $\left._{f}\right)$ : 


$$
\mathrm{Age}_{\mathrm{f}}=\mathrm{Age}_{\mathrm{c}}+\left(\left(\mathrm{Mo}_{\mathrm{c}}-\mathrm{Mo}_{\mathrm{b}}\right) / 12\right)
$$

181

182

183

184

185

186

187

188

189

190

191

192

193

194

195

196

197

198

199

200

201

202

\section{Body-size relationships}

For weight - length relationships we regressed $W$ on TL and FL $(n=577)$ using all fish with both lengths and whole weights sampled for this study, examining both a non-linear fit using nonlinear least squares estimation (vers. 9.4; SAS Institute, Inc., 1987) and a linearized fit of the log-transformed data. Residuals were examined to determine which regression provided the best fit. For length-length relationships, we regressed TL on FL and FL on TL $(n=622)$ using linear regression.

\section{Natural mortality}

We estimated the instantaneous rate of natural mortality $(M)$ of jolthead porgy using several methods:

(1) Hewitt \& Hoenig's (2005) longevity mortality relationship

$$
M=4.22 / t_{\max }
$$

where $t_{\max }$ is the maximum age of the fish in the sample;

(2) Charnov, Gislason \& Pope's (2013) method using life history parameters

$$
M=\left(L / L_{\infty}\right)^{-1.5} K
$$

where $L_{\infty}$ and $K$ are the von Bertalanffy growth equation parameters and $L$ is fish length at age;

(3) Then et al.'s (2015) $t_{\max }$-based estimator

$$
M=4.899 t_{\max }{ }^{-0.916}
$$

and (4) Then et al.’s (2015) growth-based estimator

$$
M=1.118 K^{0.73} L_{\infty}^{-0.33} \text {. }
$$

The equation of Hewitt \& Hoenig (2005) and the two equations from Then et al. (2015) use either maximum age or von Bertalanffy growth parameters to generate a single point estimate. 
203 The Charnov, Gislason \& Pope (2013) method, which incorporates life history information via

204 the growth parameters, is based upon evidence suggesting that $M$ decreases as a power function

205 of body size. This method generates age-specific rates of $M$ and has recently been used in

206 Southeast Data Assessment and Review (SEDAR) stock assessments (SEDAR, 2017a).

207 The estimated percent of the population to survive to the oldest observed age in the

208 population was calculated with the natural mortality rates applied to the fully-recruited ages in

209 the fishery (modal age +1$)$. The following equation was used:

$210 \%$ survivorship $=100 *\left(\exp \left(-\sum\left(\right.\right.\right.$ Mage $_{\mathrm{f}}-$ Mage $\left.\left._{\mathrm{o}}\right)\right)$

211 where Mage $_{\mathrm{f}}=$ natural mortality at the first age of full recruitment and Mage $_{\mathrm{o}}=$ natural mortality

212 at the oldest age in the population.

213 Total and Fishing Mortality

214 The total instantaneous mortality rate $Z$ was estimated using a catch curve analysis of the age-

215 frequency of the samples (Beverton and Holt, 1957). We used only fully recruited ages (modal

216 age plus one), since the age group at the top of the catch curve may not yet be fully vulnerable to

217 the fishing gear (Everhart et al., 1975). The instantaneous rate of fishing mortality, $F$, was

218 estimated by subtracting $M$ from $Z$.

219

220

\section{RESULTS}

\section{Reproductive Seasonality}

Gonads were collected from 178 individuals (22 males, 156 females). Due to lack of samples we did not analyze male reproductive seasonality. Jolthead porgy exhibit increasing ovary

224 development from December to March, with peak spawning in March, as indicated by

225 gonadosomatic index (Fig. 1a). This trend is supported by a plot of relative proportion of gonad 
226 stage by month (Fig. 1b), showing fish with primarily hydrated oocytes from December - March,

227 followed in subsequent months by a preponderance of fish in a regressing or resting gonad stage.

228 The lack of gonad samples from June through September is likely due to a combination of two

229 factors. First, the species was not encountered as frequently by samplers during the months of

230 June through August. The reason for this temporal absence in the landings is unknown, but it is

231 apparent in the otolith collections as well (Fig. 2). Secondly, it is probable that any jolthead

232 porgy that were encountered were in a resting/regressing stage and the gonads were overlooked.

233 This is a plausible explanation for why no gonad samples were taken in September, when sample

234 sizes rebounded.

235

236

237

238

239

240

241

242

243

244

\section{Age determination and timing of opaque zone formation}

We sectioned 638 jolthead porgy sagittae collected. Opaque zones were counted on 635 (99.5 \%) jolthead porgy sections. Three samples were determined to be illegible and excluded from the analyses.

We were able to assign an edge type to $99 \%$ of our samples $(n=633)$ for our analysis of opaque zone formation timing. Jolthead porgy otoliths exhibited opaque zones on the margin March - June, with a peak in April (Fig. 2). Opaque zones on the edge were absent from July through February. A shift to narrow translucent edge was noted from May to September. Moderate to wide translucent edges were found October through January, and the widest translucent edge was found during February and March, prior to peak opaque zone formation in April. We assumed that opaque zones on jolthead porgy otoliths were annuli.

Calendar ages were assigned as follows: for fish caught January through June and having an edge type of 3 or 4 , the annuli count was increased by one; for fish caught in that same time 
248 period with an edge type of 1 or 2 , calendar age was equivalent to annuli count; for fish caught

249 from July to December, the calendar age was equivalent also to the annuli count.

250 Opaque zones on jolthead porgy otoliths were clear and easy to interpret (Fig. 3) and edge

251 types were assigned consistently between readers. Between-reader APE was 0.06\% $(n=520)$,

252 meeting Campana's (2001) acceptable value for APE (5\% for species of moderate longevity and

253 reading complexity). In fact, the readings only disagreed on 2 of 520 samples and only by \pm one

254 year in both cases. Both readers noted that those two otolith samples were of marginal quality.

255 Consensus on between-reader counts was reached on all samples, and no samples were excluded

256 from further analyses. The opaque zones were easy to trace from the sulcal groove out into the

257 lateral plane on the dorsal side of the sections. The opaque zones were also matched with those

258 on the ventral side, but due to refraction of the crystalline matrix on the ventral portion, the most

259 consistent counts were made on the dorsal portion.

260 Growth

261 Growth of jolthead porgy was modeled using fractional ages based on the birth month, or

262 month of peak spawning, of March determined from the reproductive samples collected. Jolthead

263 porgy in this study ranged from $235-680 \mathrm{~mm}$ TL and ages $1-13$, but only five fish were older

264 than age-8 (Table 1). The standard deviation of length-at-age increased with age, but the

265 coefficient of variation (CV) remained relatively constant. Thus, we assumed constant CV in our

266 model estimation. Growth is described by the following equation:

267

$$
L_{t}=737\left(1-e^{-0.14(t+2.02)}\right)(n=635 ; \text { Fig. } 4) \text {. }
$$

268 While our data included large numbers of aged 2-4 fish, we had just one fish smaller than 250

$269 \mathrm{~mm}$ TL. This lack of smaller fish is likely explained by gear selectivity, as our samples were all

270 fishery-dependent and fish smaller than this size are likely unable to recruit to the hooks used in 
271 the fishery, or by fishers not retaining small fish in their catch, especially in light of the bag-limit

272 regulations. Therefore we re-estimated the growth model using the method of McGarvey \&

273 Fowler (2002), which uses a left-truncated normal probability density function of length to adjust

274 for the bias imposed by minimum size limits (or some other selectivity imposed by the fisheries)

275 by assuming a zero probability of capture below the minimum size limit. We assumed a de facto

276 minimum size limit for this analysis of $250 \mathrm{~mm}$ TL and estimated the growth model parameters

277 with $t_{0}$ freely estimated by the model. This procedure has the effect of pulling the growth curve

278 down to simulate smaller fish length-at-age for the youngest ages. We applied the full,

279 untruncated normal likelihood to specimens in the study not subject to the minimum size limit.

280 Parameters were estimated by minimizing the negative sum of log-likelihoods using AD Model

281 Builder estimation software. The resulting growth model is:

282

$$
L_{t}=724\left(1-e^{-0.14(t+1.9)}\right)(n=634 \text {, Fig. 4). }
$$

\section{Body-Size Relationships}

284 Statistical analyses revealed an additive error term (variance not increasing with size) in the

residuals of the $W-$ TL and $W-$ FL relationships for jolthead porgy, indicating that direct non-

286 linear fits of the data were appropriate. The relationships are described by the following

287 equations:

$W=1.1 \times 10^{-5} \mathrm{TL}^{3.05}(n=577)$ and $W=4.2 \times 10^{-5} \mathrm{FL}^{2.90}(n=577)$.

The relationships between TL and FL are described by the equations

$$
\mathrm{TL}=1.09 \times \mathrm{FL}+20.44\left(n=622 ; r^{2}=0.99 ; p<0.0001\right) \text { and }
$$

$$
\mathrm{FL}=0.90 \times \mathrm{TL}-14.26\left(n=622 ; r^{2}=0.99 ; p<0.0001\right) .
$$


Natural mortality $(M)$ was estimated to be $0.32 \mathrm{y}^{-1}$ for jolthead porgy using Hewitt \&

294 Hoenig's (2005) method integrating all ages into a single point estimate, using the maximum age

295 from our study of 13 yrs. $M$ was estimated to be $0.47 \mathrm{y}^{-1}$ using Then et al.'s (2015) $t_{\max }$ - based

296 method and $0.03 \mathrm{y}^{-1}$ using their growth-based equation. Age-specific estimates of $M$ using

297 Charnov, Gislason \& Pope (2013) are presented in Table 1. We used the midpoint of each age

298 (e.g., 0.5, 1.5, 2.5, etc.) to calculate age-specific $M$, because the Charnov, Gislason \& Pope

299 (2013) method cannot mathematically calculate $M$ for age-0. Also, for stock assessment purposes

300 where the integer age is used to describe the entire year of the fish's life, the mid-point gives the

301 median value of $M$ for that age.

302 When considering the cumulative estimate of survivorship on the fully recruited age to the 303 oldest age, the Hewitt \& Hoenig (2005) method estimates $2.8 \%$ survivorship, while the

304 Charnov, Gislason \& Pope (2013) estimate is $8.3 \%$ and Then et al's (2015) aged-based estimate 305 is $0.6 \%$. When estimating survivorship only on the fully recruited ages, this estimate omits a 306 large amount of mortality that occurs on younger fish, thus affecting the survivorship estimate. If

307 we use all ages $(0-13)$, survivorship is estimated to be $1.1 \%$ using Hewitt \& Hoenig (2005)

308 constant $M, 1.3 \%$ using the Charnov, Gislason \& Pope (2013) age-specific $M$, and $0.1 \%$ using

309 Then et al.’s (2015) age based estimate.

310 Total and Fishing Mortality

311 Jolthead porgy were fully recruited to the fishery by age-3. Catch curve analysis of the sample 312 age frequency plot results in an estimate of $Z=0.70$. If we use the Hewitt and Hoenig (2005) 313 point estimate of $M$, this results in a value of fishing mortality $F=0.38$. If we use the age314 varying method of Charnov, Gislason \& Pope (2013), then our estimates of $F$ range from 0.35 3150.50 for ages $3-9$. 


\section{DISCUSSION}

Otolith edge analysis demonstrated that jolthead porgy deposited one annulus per year from March-June, with peak annulus formation occurring in April. These results are similar to timing of annulus formation for other members of the family Sparidae in the SEUS, which tend to form annuli in the late spring-summer months (knobbed porgy - June and July for fish from North July for fish from the South Atlantic Bight, Waltz, Roumillat \& Wenner, 1982; littlehead porgy, Calamus proridens Jordan and Gilbert 1884 - April for fish from the eastern Gulf of Mexico, Tyler-Jedlund \& Torres, 2015; red porgy, Pagrus pagrus Linnaeus 1758 - March through May, with peak in April for fish from North Carolina through southeast Florida, Potts \& Manooch, 2001).

Growth was rapid, with jolthead porgy attaining average observed sizes of 300, 418 and 545 mm TL by ages 1, 4 and 8 respectively (Table 1). Our study contained only five fish older than age-8. Though jolthead porgy is the largest of the Calamus species, this fish has a similar longevity to what has been found in studies of C. nodosus (Borden, 2001), C. leucosteus (Waltz, Roumillat \& Wenner, 1982) and C. proridens (Tyler-Jedlund \& Torres, 2015), maximum ages of 12,12 , and 10 years, respectively, and each study also had few fish older than age- 8 . Two of the studies, Waltz, Roumillat \& Wenner (1982) and Tyler-Jedlund \& Torres (2015) collected the majority of their specimens from fishery-independent trawl surveys which fished in $11-20 \mathrm{~m}$ at the shallowest depths, but then supplemented their collections for larger fish from offshore hard bottom and reef habitats. These studies were able to collect small, juvenile fish (50 and $76 \mathrm{~mm}$ 
339 with depth of fishing. The other studies obtained their samples from offshore commercial and

340 recreational fishing on hard bottom or reef habitats, and were unable to collect fish smaller than

$341 \sim 250 \mathrm{~mm}$ TL. We theorize that all four species discussed here exhibit a general ontogentic shift

342 from shallow water to deeper water as they grow and mature. The samples from this study were

343 primarily from the recreational fishery. The SEUS commercial fishery tends to fish in deeper

344 water, and if the species does move to deeper water as it gets older, as suggested by studies of

345 other Calamus spp., then the largest and oldest fish may never be available for age-growth

346 studies, leading us to underestimate jolthead porgy's longevity or even the maximum size, 760

347 mm FL (849 mm TL; Froese \& Pauly, 2017). The smallest fish in our study, $235 \mathrm{~mm}$ TL, was

348 age-2 and all age- 1 fish were $\geq 250 \mathrm{~mm}$. This lack of small, young fish is common to studies

349 dominated by fishery-dependent samples and can lead to problems in estimating the growth

350 curve for the youngest ages. Because of the lack of youngest fish in this study, the corresponding

351 growth curve for young fish should be interpreted with caution. We attempted to account for this

352 issue by re-estimating our growth parameters using a correction to adjust for the bias imposed by

353 fishery selectivity. This procedure had the effect of slightly reducing the initial trajectory of the

354 growth curve (Fig. 4).

355 The difference in predicted sizes at the younger ages between estimation methods (Fig. 4) was

356 slight, likely due to the number of age- 1 fish in our collection. Age- 0 fish were not retained in

357 the fishery landings. The von Bertalanffy growth model does not capture growth of fish beyond

358 the data points used to estimate the parameters. Thus, these predicted values should be used with

359 the knowledge that they carry added uncertainty.

360 We compared von Bertalanffy growth parameters for the four most common Calamus spp.

361 from the SEUS in Table 2. Jolthead porgy has a predicted maximum size almost twice as large as 
362 C. nodosus, C. leucosteus and C. proridens, though the age ranges are similar. The Brody growth

363 coefficient $K$, the rate of attainment of maximum size, was lowest for jolthead porgy, 0.14 , which

364 is about half of the values for the other species. This is expected given the inverse relationship

365 between $L_{\infty}$ and $K$.

366 Natural mortality $(M)$ of wild populations of fish is difficult to measure but is an important

367 input variable into stock assessments. We believe that the estimate of $M$ derived from the

368 maximum-age-based method of Hewitt \& Hoenig (2005) obtained in this study, $M=0.32$, was a

369 reasonable estimate for the fully recruited ages in our study, as it compared favorably with the

370 estimate of $M=0.38$ for black sea bass as used in SEDAR 25 (SEDAR, 2017b). Though the

371 estimate of $M$ for black sea bass was derived using the method of Hoenig (1983), when

372 computing $M$ using the Hewitt and Hoenig (2005) method, the value was the same. Both species

373 have similar maximum age (11 years for black sea bass) and length. We do not believe this is a

374 suitable estimate of $M$ for all ages, because younger fish are more vulnerable to predation, and

375 thus likely have higher mortality rates. The age-varying $M$ calculated using Charnov, Gislason \&

376 Pope (2013) seems a more appropriate estimator for the younger ages. The initial Charnov,

377 Gislason \& Pope (2013) estimates of $M$ starting with the fully recruited age of 3 was

378 approximately equal to the Hewitt \& Hoenig (2005) estimate, which suggests that the fish's

379 initial fast growth allowed it to reach a size less vulnerable to predation. The age-specific

380 estimates of $M$ for the older ages continue to decrease until stabilizing at 0.17 at age-12 (Table

381 1). The maximum-age-based method of Then et al. (2015) resulted in a point estimate equal to

382 0.47, while Then et al.'s (2015) growth-based estimator resulted in a value of 0.03 . When

383 deciding which estimator to use when they are so widely varying, the likely reliability of the

384 input to the estimator should be considered. Generally, we do not believe that purely size-based 
385 estimates, as in the case of Then et al.'s (2015) growth-based estimator, are appropriate. Then et

386 al. (2015) did caution about using this estimator, which included a high variance about the

387 estimate. Jolthead porgy, compared to other co-occurring reef fish such as species of Lutjanidae,

388 are shorter-lived and occupy a lower trophic level, so we expect $M$ to be higher than estimates

389 for Lutjanids. The estimate of $L_{\infty}$ is limited by the samples used to develop the model and is

390 tightly, inversely-correlated with $K$. Because of the lack of small fish to accurately describe

391 initial growth at the youngest ages, which affects the trajectory of the growth curve and thus the

392 value of the asymptotic length, we are more confident using the maximum age versus the

393 estimate of $L_{\infty}$ to estimate $M$. We have some confidence in the maximum age found in this study

394 because it is similar to what was found for several congeners (Table 2), while our maximum size

395 if $680 \mathrm{~mm}$ TL is quite a bit smaller than the largest recorded jolthead porgy ( $760 \mathrm{~mm}$ FL, or 849

$396 \mathrm{~mm}$ TL. We recognize the possibility that the maximum age of jolthead is greater than the 13

397 years that we found, but we have found nothing in the literature to show that is indeed fact.

398 When estimating survivorship only on the fully recruited ages, this estimate omits a large

399 amount of mortality that occurs on younger fish, thus affecting the survivorship estimate. Few of

400 the fish in our samples were older than 8 yrs ( 5 of 635). Though our samples are limited for this

401 study, the age frequency suggests that the chance of survivorship to the oldest age may truly be

402 about $1.1 \%$. There is evidence that selectivity of hook and line gear is not dome-shaped for red

403 porgy taken in commercial or headboat fisheries (SEDAR 2012). If true for jolthead porgy, it

404 suggests our study had the potential to collect the largest and oldest fish in the population (but

405 see discussion in the paragraph below). These observations give weight to the argument that the

406 Then et al. (2015) age-based method overestimated $M$, and the Charnov, Gislason \& Pope (2013)

407 estimate of $M$ at age may have under-estimated. Because we believe that the Hewitt \& Hoenig 
408 (2005) estimate for fully recruited ages may be the best estimate, but not appropriate for the 409 smallest, youngest fish, we suggest that the Charnov, Gislason \& Pope (2013) estimates be 410 scaled to the Hewitt \& Hoenig (2005) estimate.

411 Our preliminary estimates of total mortality, $Z=0.70$, and fishing mortality, $F=0.38$, are 412 somewhat difficult to interpret. A basic assumption of the catch curve analysis method we used 413 to calculate $Z$ is that the sample is representative of the population. While we feel our sampling 414 fairly represents the fished population in the SEUS, it is possible that the portion of the 415 population vulnerable to the commercial fishery was underrepresented by our sampling. This 416 could result in a biased estimate of maximum age and growth parameters, which would have an 417 effect on our estimates of $M$ and thus $Z$. Managers should thus interpret these results with 418 caution.

419 This is the first published study of jolthead porgy life history. We documented the first data 420 on reproductive seasonality of the species, showing a discrete spawning season during the late winter months. We have shown that otolith sections of jolthead porgy contain annuli that are remarkably easy to enumerate and that otolith sections are reliable structures for aging. Opaque 423 zones on jolthead porgy sagittae are assumed to be deposited once a year March - June, and the 424 growth trajectory follows a similar path to its smaller congeners. Our estimate of $M$ based on 425 Hewitt \& Hoenig (2005) is reasonable for a species with moderately fast growth and longevity of 426 at least 13 years. We provide the first preliminary estimates of total and fishing mortality for this 427 species. These results begin to fill an information gap for this data poor species and should allow 428 fishery regulators to set future ACLs that are based on better scientific data such as life history 429 parameters, versus less than optimum data that has been used in the past for data-limited species 430 (e.g., catch histories), as pointed out by Carruthers et al., 2017. 


\section{ACKNOWLEDGEMENTS}

433

434

435 436

437

438

439

440

441

442

443

444

445

446

447

448

449

450

451

452

453

We gratefully acknowledge the many NMFS headboat and commercial port samplers over the years whose efforts made this study possible. R Munoz, R Allman, T Kellison and two anonymous reviewers provided reviews which greatly improved the manuscript.

Beamish RJ, Fournier DA. 1981. A method for comparing the precision of a set of age determinations. Can J Fish Aq Sci. 38:982-983. http://dx.doi.org/10.1139/f81 - 132.

Beverton RJH, Holt SJ. 1957. On the dynamics of exploited fish populations. Fish. Invest. Ser. II Mar. Fish., Vol. 19, G.B. Minist. Agric. Fish. Food., pp. 1 - 533.

\section{Borden SH. 2001. Age growth and reproduction in the northern-most population of knobbed} porgy (Calamus nodosus). M.S. Thesis, University of North Carolina-Wilmington, Wilmington, NC.

Brown-Peterson NJ, Wyanski DM, Saborido-Rey F, Macewicz BJ, Lowerre-Barbieri SK. 2011. A standardized terminology for describing reproductive development in fishes. Marine and Coastal Fisheries 3:52-70.http://dx.doi.org/10.1080/19425120.2011.555724.

Burton ML. 2001. Age, growth, and mortality of gray snapper from the east coast of Florida. US 
Fish Bull. 99:245-256.

455

456

457

458

459

460

461

462

463

464

465

466

467

468

469

470

471

472

473

474

475

476

Campana SE. 2001. Accuracy, precision and quality control in age determination, including a review of the use and abuse of age validation methods. J Fish Biol 59:197-242. http://dx..doi.org/10.1111/j.1095-8649.2001.tb00127.x

Carruthers TR, Punt AE, Walters CJ, MacCall A, McAllister MK, Dick EJ, Cope J. 2017. SEDAR 50-RD41. Evaluating methods for setting catch limited in data-limited fisheries. Available from: http://sedarweb.org/docs/wsupp/S50_RD41_Carruthers_etal2014.pdf

Charnov EL, Gislason H, Pope JG. 2013. Evolutionary assembly rules for fish life histories. Fish Fisheries. 14:212-224. http://dx.doi.org/10.1111/j.1467-2979.00467.x

Claro R, Lindeman KC, Parenti LR. 2001. Ecology of the marine fishes of Cuba. Smithsonian Institution Press. Washington DC.

Dixon RL, Huntsman GR. 2004. Estimating catches and fishing effort of the southeast United States headboat fleet, 1972-1982. SEDAR 7_DW19. Accessed at sedarweb.org/s7dw19estimating-catches-and-fishing-effort-southeast-united-states-headboat-fleet-1972-1982.

Dubovitskij AA. 1974. Sexual ratio and population size of Calamus bajonado (Bloch and Schneider, 1801) in the Campeche Bank. In: A. S. Bogdanov, ed. Joint Soviet-Cuban Fisheries Investigations Pishevaia Promishlennost, Moscow, vol. 4:177-181. 
478 Everhart WH, Eipper AW, Youngs WD. 1975. Principles of Fishery Science. Cornell University $479 \quad$ Press, Ithaca, NY.

480

481

482

483

484

Froese, R. and D. Pauly. Editors. 2017. FishBase. World Wide Web electronic publication. www.fishbase.org, version (02/2017). Available from http://www.fishbase.org/Summary/SpeciesSummary.php?ID=1221\&AT=jolthead +porgy

485

Harris PJ, Wyanski DM, White DB, Mikell PP, Eyo PB. 2007. Age, growth, and reproduction of greater amberjack off the southeastern U.S. Atlantic coast. Trans Am Fish Soc 136:15341545. http://dx.doi.org/10.1577/T06-113.1

489

490

491

492

493

494

495

496

497

498

499 (Accessed May 22, 2017).

Hewitt DA, Hoenig JM. 2005. Comparison of two approaches for estimating natural mortality based on longevity. US Fish Bull. 103:433-437.

Horvath ML, Grimes CB, Huntsman GR. 1990. Growth, mortality, reproduction and feeding of knobbed porgy, Calamus nodosus, along the southeastern United States coast. Bulletin of Marine Science 46(3):677-687.

McGarvey R, Fowler AJ. 2002. Seasonal growth of King George whiting (Sillaginodes punctata) estimated from length-at-age samples of the legal-size harvest. US Fish Bull. 100:545558. 
501 Potts JC, Manooch CS III. 1995. Age and growth of red hind and rock hind collected from North 502 Carolina through the Dry Tortugas, Florida. Bull Mar Sci. 56:784-794.

503

504 Potts JC, Manooch CS III. 2001. Estimated ages of red porgy (Pagrus pagrus) from fishery505 dependent and fishery-independent data and a comparison of growth parameters. US $506 \quad$ Fish Bull. 100:81-89.

507

508 Potts JC, Burton ML, Myers AR. 2016. Age, growth and natural mortality of schoolmaster 509 (Lutjanus apodus) from the southeastern United States. PeerJ 4e2543; DOI

$510 \quad 10.7717 /$ peerj.2543

511

512 Randall JE, Caldwell DK. 1966. A review of the sparid fish genus Calamus, with descriptions 513 of four new species. Bulletin of the Los Angeles County Museum of Natural History $514 \quad$ Science 2:1-46.

515

516 SAFMC 2017. Jolthead Porgy: Fish ID and Regs: Regulations by Species. Available at: 517 http://safmc.net/regulations/regulations-by-species/jolthead-porgy/ (Accessed March 17, 518 2017).

519

520 SAS Institute, Inc. 1987. SAS/STAT guide for personal computers, version 6 edition: SAS 521 Institute: Cary North Carolina. 
523 SEDAR. 2012. SEDAR41 Stock assessment of red porgy off the Southeastern United States.

524

525

526

527

528

529

530

531

532

533

534

535

536

537

538

539

540

541

542

543 Then AY, Hoenig JM, Hall NG, Hewitt DA. 2015. Evaluating the predictive performance of

544

545
SEDAR Update Assessment.

Available from http://sedarweb.org/docs/suar/2012_SARPUpdate_Revised.pdf

(Accessed June 13, 2017).
SEDAR. 2017a. SEDAR41 Stock assessment of red snapper off the Southeastern United States. Available from http://sedarweb.org/docs/sar/S41_SA_RS_AWReportCorrected_4.24.2017_0.pdf (Accessed June 13, 2017).

SEDAR. 2017b. SEDAR25 South Atlantic black sea bass stock assessment report. Available from http://sedarweb.org/docs/wsupp/S56 RD02 S25 SAR.pdf (Accessed June 13, 2017).

Sedberry, GR. 1989. Feeding habits of whitebone porgy, Calamus leucosteus (Teleostei: Sparidae), associated with hard bottom reefs off the southeastern United States. Fishery Bulletin 87:935-944.

Smith CL. 1997. National Audubon Society field guide to tropical marine fishes of the Caribbean, the Gulf of Mexico, the Bahamas and Bermuda. Alfred A. Knopf Inc. 720 p. 
547 Tyler-Jedlund AJ, Torres JJ. 2015. Age, growth, and reproduction of the littlehead porgy,

548 Calamus proridens, from the eastern Gulf of Mexico. Bull. Mar. Sci. 91 (2):101-123.

$549 \quad$ http://dx.doi.org/10.5343/bms.2014.1015

550 von Bertalanffy L. 1938. A quantitative theory of organic growth. Hum Biol. 10:181-243.

551

552 Waltz, CW, Roumillat WA, Wenner CA. 1982. Biology of the whitebone porgy, Calamus

553 leucosteus, in the South Atlantic Bight. Fishery Bulletin 80(4):863-874.

554

555

556

557

558 MLB, JCP: National Marine Fisheries Service, 101 Pivers Island Rd., Beaufort NC 28516-9701;

559 JP: 224 Pelican Dr., Atlantic Beach NC 28512; AP: 213 West Indies Rd., Tavernier FL 33070. 


\section{Table $\mathbf{1}$ (on next page)}

Observed and predicted mean total length (TL) and natural mortality at age $(M)$ data for jolthead porgy. 
1 Table 1. Observed and predicted (von Bertalanffy, 1938) mean total length (TL), measured in

2 millimeters, and natural mortality at age ( $M$, Charnov, Gislason \& Pope, 2013) data for jolthead

3 porgy (Calamus bajonado) collected from 2008-2016 along the Florida coast. Standard errors of

4 the means (SE) are provided in parentheses.

\begin{tabular}{cccccc}
\hline & & & & Predicted & \\
Age & $n$ & Mean TL $( \pm$ SE $)$ & TL range & TL & $M \mathrm{y}^{-1}$ \\
\hline 1 & 18 & $300(8)$ & $250-375$ & 254 & 0.58 \\
2 & 235 & $320(2)$ & $235-405$ & 317 & 0.44 \\
3 & 159 & $370(3)$ & $284-520$ & 372 & 0.35 \\
4 & 120 & $418(4)$ & $280-535$ & 420 & 0.30 \\
5 & 46 & $452(8)$ & $329-600$ & 461 & 0.27 \\
6 & 26 & $492(11)$ & $380-610$ & 497 & 0.24 \\
7 & 18 & $517(20)$ & $332-640$ & 529 & 0.22 \\
8 & 8 & $545(23)$ & $470-632$ & 556 & 0.21 \\
9 & 2 & $523(48)$ & $475-570$ & 579 & 0.20 \\
12 & 2 & $675(5)$ & $670-680$ & 633 & 0.17 \\
13 & 1 & 680 & -- & 647 & 0.17 \\
\hline
\end{tabular}

5 


\section{Table 2 (on next page)}

Comparison of von Bertalanffy growth parameters for Calamus spp. from the US southeast region. 
1

2 Table 2. Comparison of von Bertalanffy growth parameters of Calamus spp. from the US

3 Southeast region. Standard errors of the parameter estimates for this study are provided in 4 parentheses below the estimates.

5

\begin{tabular}{llcccc}
\hline \multicolumn{1}{c}{ Species } & \multicolumn{1}{c}{ Study } & Max Age & $\mathbf{L}_{\infty}$ & $\mathbf{K}$ & $\mathbf{t}_{\mathbf{0}}$ \\
\hline C. nodosus & Borden 2001 & 12 & $357 \mathrm{~mm} \mathrm{FL}$ & 0.26 & -1.81 \\
C. leucosteus & Waltz, Roumillat \& & 12 & $362 \mathrm{~mm} \mathrm{FL}$ & 0.26 & -1.40 \\
& Wenner 1982 & & & & \\
C. proridens & $\begin{array}{l}\text { Tyler-Jedlund \& } \\
\text { Torres 2015 }\end{array}$ & 10 & $306 \mathrm{~mm} \mathrm{FL}$ & 0.25 & -1.69 \\
& This study & & & & \\
& & 13 & $737 \mathrm{~mm} \mathrm{TL}$ & 0.14 & -2.02 \\
& & & $(5.67)$ & $(0.02)$ & $(0.30)$ \\
\hline
\end{tabular}

6 
Figure 1 (on next page)

Reproductive seasonality of jolthead porgy

Examination of reproductive seasonality of jolthead porgy (Calamus bajonado) collected from Florida in 2015 - 2016 as determined by (A) mean monthly gonadosomatic index of females sampled, and (B) relative proportion of female gonadal development by month, determined macroscopically. Sample size for each month is noted on the figure with the associated graphical point. 

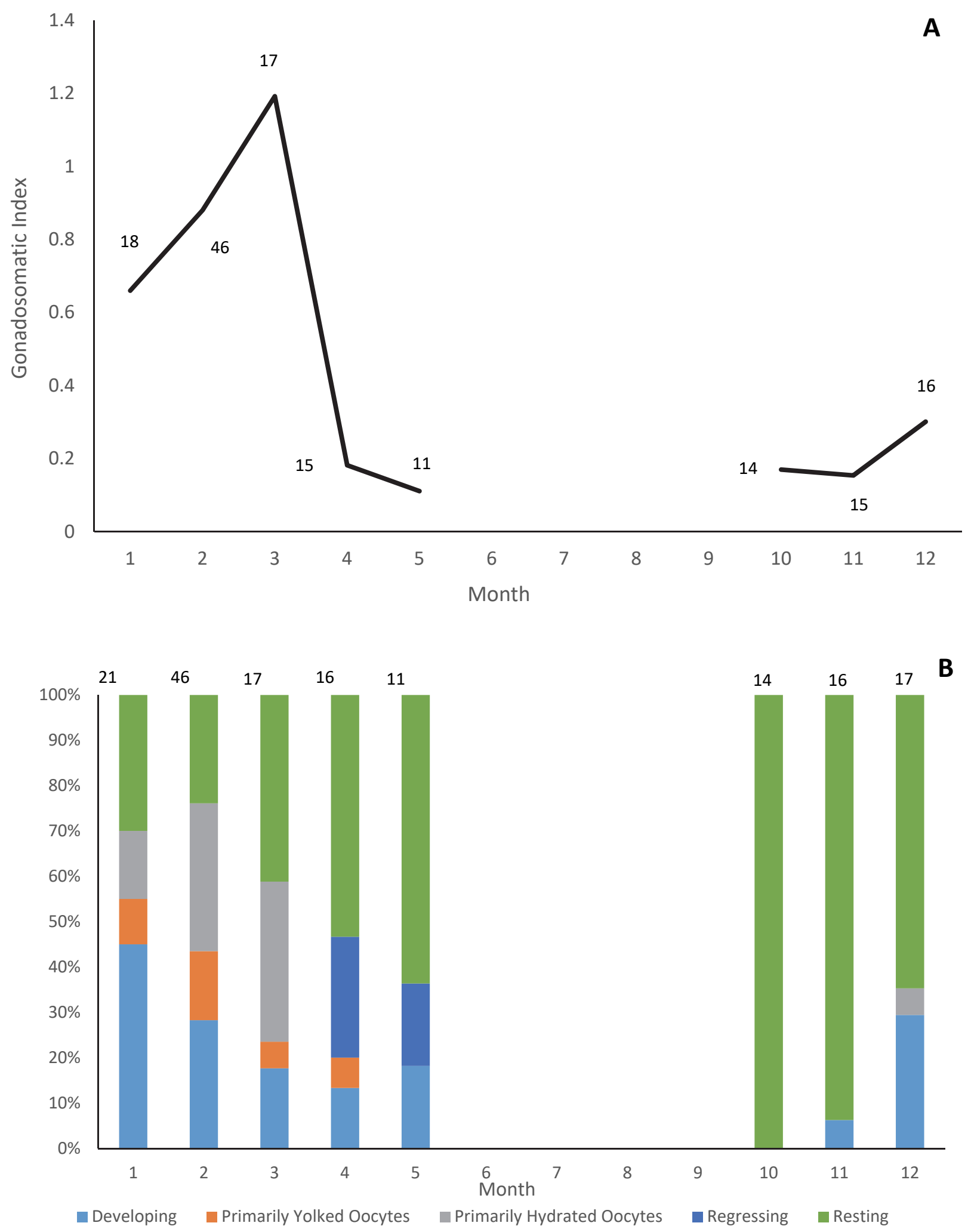
Figure 2 (on next page)

Analysis of edge type of otoliths of jolthead porgy.

Monthly percentages of all edge types for jolthead porgy (Calamus bajonado) collected from Florida in 2008 - 2016. Edge codes: 1=opaque zone on edge, indicating annulus formation; $2=$ small translucent zone, $<30 \%$ of previous translucent zone; $3=$ moderate translucent zone, $30-60 \%$ of previous translucent zone; $4=$ wide translucent zone, $>60 \%$ of previous translucent zone. Sample sizes are shown above columns. 


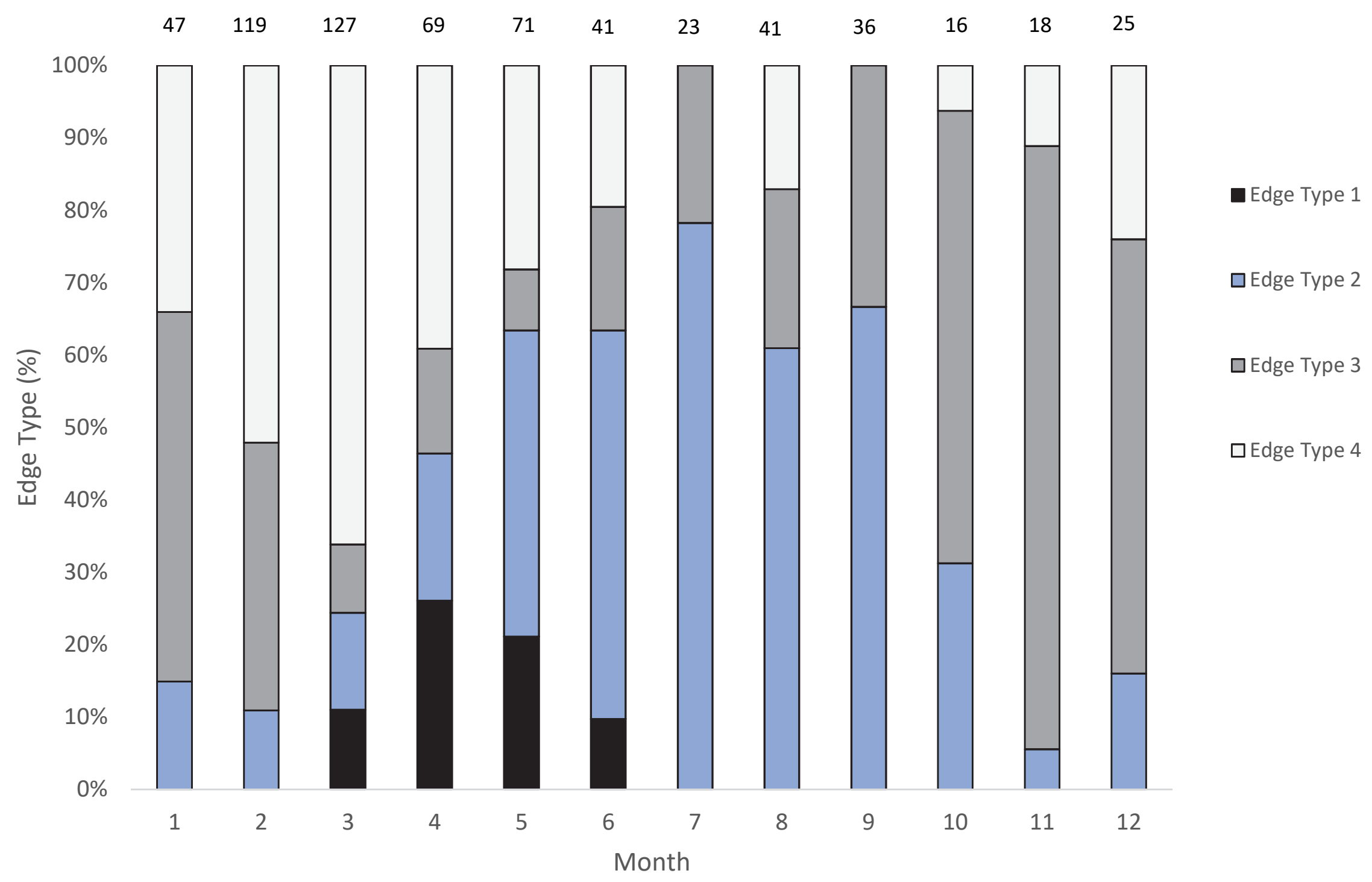




\section{Figure 3}

Photographs of jolthead porgy otolith sections.

Sections from otoliths of jolthead porgy (Calamus bajonado): (A) $397 \mathrm{~mm}$ TL 3-yr old; (B) 527 mm TL 6-yr old; (C) $570 \mathrm{~mm}$ TL 9-yr old. Age was determined by counting opaque zones along the dorsal axis and sulcus using transmitted light at $12.5 \mathrm{X}$ magnification. 
A.

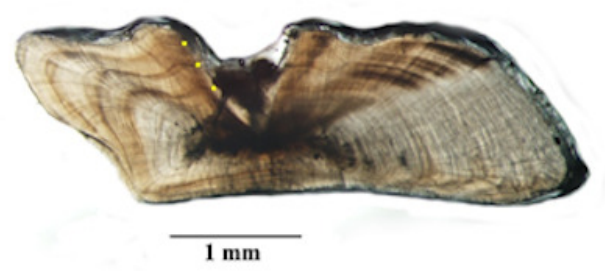

B.

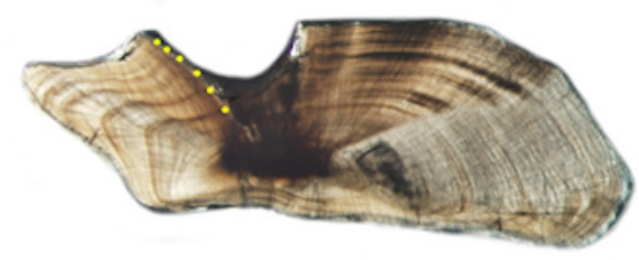

$1 \mathrm{~mm}$

C.

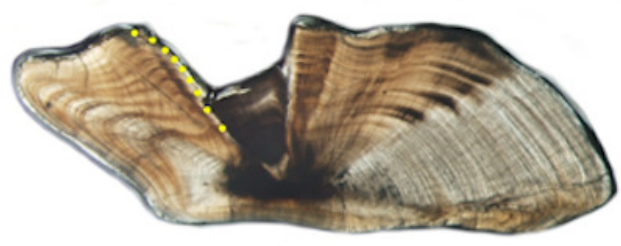

$\overline{1 \mathrm{~mm}}$ 
Figure 4(on next page)

Von Bertalanffy growth curves of jolthead porgy.

Von Bertalanffy growth curves of jolthead porgy (Calamus bajonado) collected from Florida in 2008-2016. We compare the curve corrected for bias of minimum size limits (McGarvey and Fowler 2002) with the uncorrected, unweighted and freely estimated $t_{0}$ curve. Observed sizes at fractional ages are plotted for comparison by region of capture. 


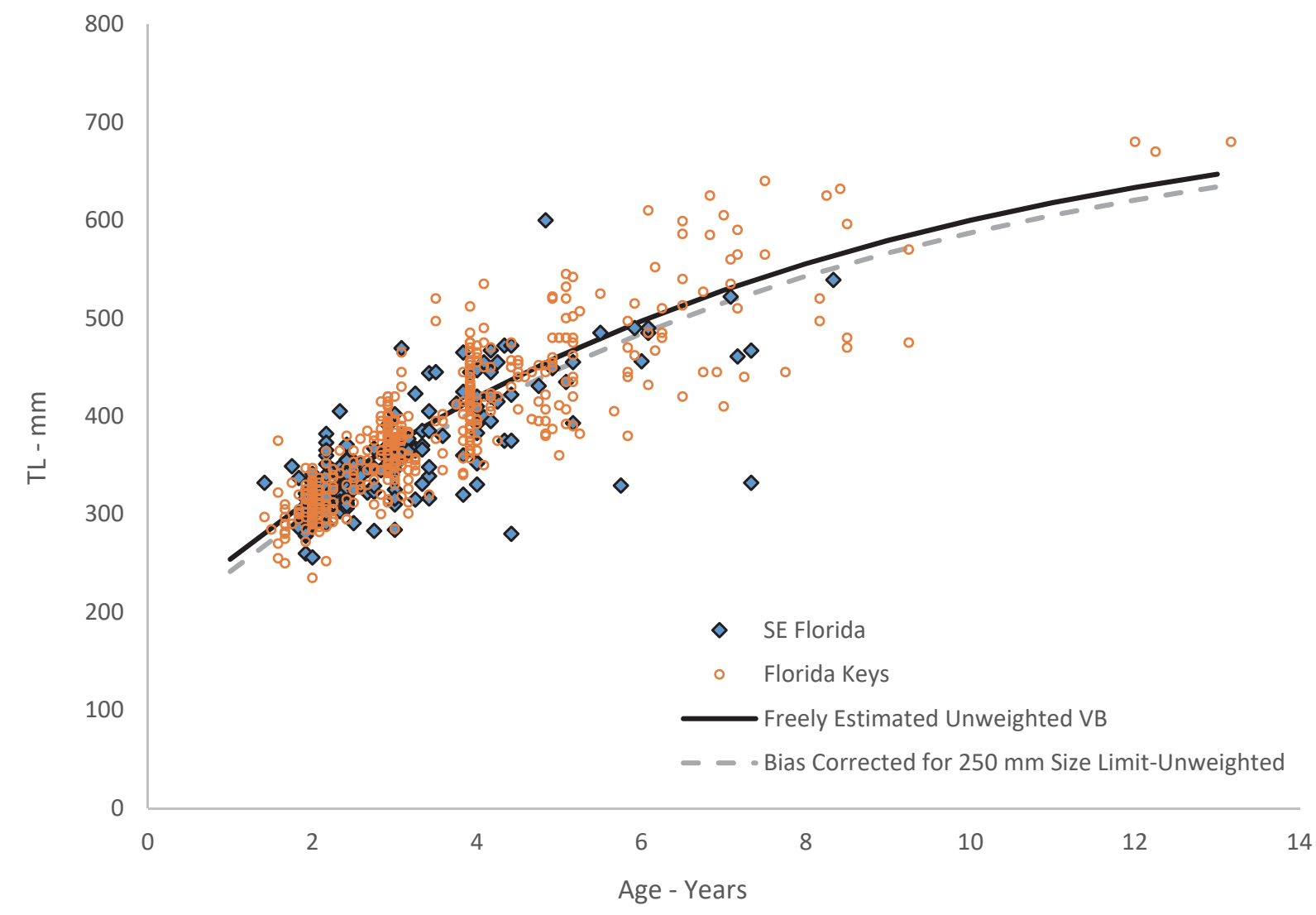

